\title{
A vigilância sanitária no Facebook: potências e fragilidades da comunicação do risco sanitário na esfera digital'
}

\section{Sanitary surveillance on Facebook: strong and weak points of sanitary surveillance communication in the internet}

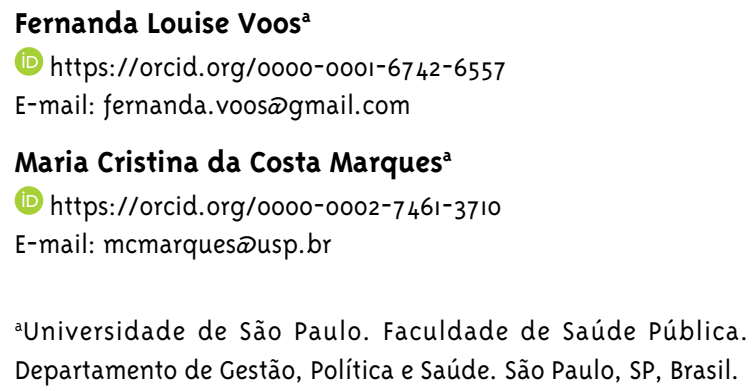
Departamento de Gestão, Política e Saúde. São Paulo, SP, Brasil.

\section{Correspondência}

\section{Fernanda Louise Voos}

Universidade de São Paulo, Faculdade de Saúde Pública, Departamento de Gestão, Política e Saúde. Av. Doutor Arnaldo, 715. São Paulo, SP, Brasil. CEP 01246-904.

\section{Resumo}

Este artigo apresenta resultados de uma pesquisa de mestrado que estudou o campo da comunicação em vigilância sanitária por meio do Facebook, a plataforma social mais popular no Brasil e que sustenta uma nova configuração comunicativa para a promoção da saúde. Busca-se revelar potências e fragilidades dos processos comunicativos digitais que evocam a midiatização do risco sanitário, a fim de verificar se essas iniciativas podem ser consideradas ferramentas de proteção social e de consolidação do direito à saúde. Primeiramente, identificamos as vigilâncias sanitárias com páginas no Facebook. Então, analisamos o que estava sendo comunicado e de que forma. O aplicativo Netvizz foi empregado na mineração dos dados. Fundamentos da análise de redes sociais e da análise de conteúdo guiaram o modelo analítico proposto. As páginas no Facebook da Agência Nacional de Vigilância Sanitária (Anvisa Oficial) e da Vigilância Sanitária do município do Rio de Janeiro (Vigilância Sanitária Rio) foram selecionadas para análise de conteúdo. Das 30 postagens de maior engajamento, publicadas entre $1^{0}$ de junho e $1^{0}$ de dezembro de 2017 , foram revelados os temas com mais reações, comentários e compartilhamentos por parte dos usuários conectados: medicamento, na página Anvisa Oficial; e controle de zoonoses, para a Vigilância Sanitária Rio. Cada tema está associado a uma diversidade de riscos sanitários, os quais revelam tensões e conflitos entre a sociedade e o poder público conectados. Acreditamos na comunicação digital como alternativa

1 Esta pesquisa foi financiada pelo Conselho Nacional de Desenvolvimento Científico e Tecnológico (CNPq). 
contemporânea para incrementar ferramentas de proteção social, fortalecer o direito à informação e, consequentemente, consolidar o direito à saúde.

Palavras-chave: Comunicação de Risco; Vigilância Sanitária; Risco Sanitário; Mídias Sociais; Direito à Saúde.

\section{Abstract}

This article presents the results of a master's program study on sanitary surveillance communication through Facebook, the most popular social platform in Brazil that offers a new communication configuration for health promotion. It verifies the strong and weak points of digital communication processes that evoke sanitary risk mediatization in order to evaluate whether such strategies can be considered tools for social protection and the consolidation of the right to health. Firstly, public organizations in Brazil identified as Sanitary Surveillance Services (SSS) that hold a fanpage on Facebook are listed. We then describe what is being communicated and how. The application software Netvizz was used for data mining. Social Network Analysis and Content Analysis were used as guides to construct an analytical model. Both the Anvisa Oficial and Vigilância Sanitária Rio fanpages were selected to content analysis of their 30 most engaged posts, published in 2017 between June $1^{\text {st }}$ and December ${ }^{\text {st }}$. Those fanpages represent the Federal Brazilian SSS (Agência Nacional de Vigilância Sanitária) and the Rio de Janeiro municipality's SSS, respectively. The topics related to the highest engagement (highest sum of reactions, comments and shares) were: medicine from Anvisa Oficial posts and zoonosis control from Vigilância Sanitária Rio posts. Each topic can be associated to many sanitary risks and reveal various tensions and conflicts between interconnected society and public health services. We believe in digital communication as a contemporary alternative to increment social protection, reinforce the right to information and, consequently, consolidate the right to health.

Keywords: Risk Communication; Sanitary Surveillance; Health Risk; Social Media; Right to Health.

\section{Introdução}

Este artigo tem como objetivo revelar potências e fragilidades da comunicação do risco sanitário por meio do Facebook, a partir de páginas de Vigilância Sanitária nesta plataforma social. Os resultados aqui demonstrados refletem parte de uma pesquisa de mestrado direcionada ao estudo da comunicação em vigilância sanitária por meio de plataformas sociais.

No Brasil e em vários outros países, especialmente na última década, temos vivenciado um aumento progressivo do uso de mídias sociais, possibilitando modos de vida que se engendram a partir das trocas entre os mundos online e offline. Estes se sobrepõem e se complementam, tornandose indissociáveis. O desenvolvimento das plataformas digitais no "modo 2.0" viabilizou participação ativa, dialogia e expressividade dos usuários em rede, o que provocou uma ruptura com a lógica linear clássica do processo comunicativo (emissor-mensagem-receptor) (Corrêa, 2015). Por essa razão, tais recursos representam uma alternativa comunicacional potente para mediar os debates sobre a promoção e proteção da saúde.

Os brasileiros somam 130 milhões de usuários ativos conectados nas mídias sociais, o equivalente a $62 \%$ da população do país. A média mundial chega a $42 \%$ de usuários ativos, mais de 3 bilhões de pessoas (Kemp, 2018).

O Facebook é a mídia social mais utilizada globalmente. A Pesquisa Brasileira de Mídia 2015 apurou que $83 \%$ dos brasileiros ${ }^{2}$ com acesso à internet possuíam conta no Facebook (Brasil, 2014). Estatísticas mais recentes indicam que o Facebook acumula, sozinho, 1 bilhão e 28o milhões de usuários ativos diários. Destes, $85 \%$ provêm de localidades fora dos Estados Unidos. Em 2018, o número de usuários mensalmente ativos da plataforma aproximou-se da marca de 2 bilhões (1 bilhão e 940 milhões) e seu acesso se deu majoritariamente (92\%) por meio de telefones móveis. ${ }^{3}$ Em janeiro de 2020, a plataforma atingiu 2,5 bilhões de usuários mensalmente ativos e $98 \%$ deles

2 O tamanho total da amostra foi fixado em 18.312 entrevistas, distribuídas em todo o país.

3 SOCIAL BAKERS. Disponível em: <https://www.socialbakers.com/statistics/facebook/>. Acesso em: 27 out. 2018. 
acessaram suas contas por meio de qualquer tipo de telefone móvel (Kemp, 2020).

Na perspectiva da promoção à saúde, acredita-se que as conversações geradas nas mídias sociais favoreçam diferentes níveis de engajamento, relacionando-se a distintos resultados, por exemplo: aumento da consciência ou do conhecimento acerca de uma informação de saúde; sentimentos de pertencimento e conexão social; envolvimento com programas de saúde - seja como participantes beneficiados por serviços ou produtos ofertados, seja como voluntários no desenvolvimento e implementação desses programas. 0 alto grau de engajamento representa que a comunicação viabilizada pelas mídias sociais ocorreu de maneira dialógica, não sendo possível obter esse resultado com um tipo de comunicação de via única, que não envolva o seu público (Neiger et al., 2013). Assim, os estudos de comunicação para a promoção da saúde buscam monitorar o engajamento como um Indicador Chave de Desempenho (em inglês, Key Performance Indicator - KPI).

Inúmeras organizações públicas da área da saúde, no Brasil e no exterior, vêm empregando as mídias sociais em sua comunicação digital. No Brasil, o Ministério da Saúde está presente no Facebook, no YouTube, no Instagram, no Twitter e no Flickr. AAgência Nacional de Vigilância Sanitária (Anvisa) manifesta-se publicamente no Twitter desde julho de 2009, e sua página oficial no Facebook foi criada em abril de 2017. No Facebook, organizações governamentais criam suas próprias páginas (fanpages) para promover a instituição e, ao mesmo tempo, midiatizar diferentes assuntos de interesse público. Os usuários com conta na plataforma podem tornar-se "fãs" ou "seguidores" da página e, assim, receber o conteúdo ali publicado (Recuero; Soares, 2013).

\section{Comunicação do risco sanitário: ferramenta da vigilância sanitária para a proteção social enquanto direito dos cidadãos}

A Constituição Federal de 1988 e a edição das leis complementares da saúde (Brasil, 1988, 1990a,199ob) oficializam a saúde no Brasil como direito fundamental do ser humano. A partir de então, a vigilância sanitária é oficialmente inserida como um dos componentes fundamentais de atuação do Sistema Único de Saúde (SUS). Na segunda metade da década de 1990, a vigilância sanitária do âmbito federal é reestruturada; a Secretaria Nacional de Vigilância Sanitária é extinta; cria-se a Anvisa, com competências definidas pela Lei no 9.782, de 26 de janeiro de 1999 (Vecina Neto; Marques; Figueiredo, 2006). Essa mesma lei define o Sistema Nacional de Vigilância Sanitária (SNVS), cuja coordenação cabe à Anvisa (Brasil, 1999).

O direito à informação e à comunicação é considerado fundamental e protegido constitucionalmente no Brasil. ${ }^{4}$ É considerada direito básico do consumidor "a proteção da vida, saúde e segurança contra os riscos provocados por práticas no fornecimento de produtos e serviços considerados perigosos ou nocivos" (Brasil, 1990a).

As ações da VS, com base normativa e jurídica, técnica e científica, organizam-se na finalidade de proteger as pessoas e as populações (Figueiredo, 2016). O controle do risco sanitário, portanto, resume a essência da função da VS e há diversas formas de fazê-lo.

Atualmente, cabe à VS atuar em um "novo modelo", aquele que "se constrói entre a necessidade de se ajustar ao regime multilateral e ao regime de política social, pelos compromissos que cercam o conceito da saúde no Estado Democrático de Direito" (Figueiredo, 2016, p. 222). Parte das estratégias da VS para consolidar esse novo modelo, em construção, decorre da ampliação dos meios de interlocução com a sociedade.

A mídia, em seus mais diversos veículos de comunicação, exerce nesse contexto um papel fundamental, seja na difusão de orientações e informações de interesse coletivo em relação a procedimentos sanitários básicos, seja na formação da opinião pública quanto à promoção da saúde como um direito do cidadão (Janes; Marques, 2007).

A comunicação do risco sanitário representa uma 
dimensão da regulação do risco sanitário que [...] concretiza a relação entre a avaliação do risco e a participação da sociedade, [...] com o objetivo de que a sociedade compreenda a informação disponível em cada momento histórico e possa realizar escolhas, sociais e individuais com a melhor informação possível. (Lucchese, 2001, p. 266)

Considerada uma tecnologia para controlar riscos, proteger e promover a saúde (Rangel-S, 2007a, 2007b), a comunicação do risco é defendida aqui como fundamental e estruturante do SUS. Mais do que um direito social que oportuniza a concretização do direito pleno à saúde, a comunicação do risco sanitário constitui-se em importante via para ampliar a participação e fortalecer os mecanismos democráticos.

\section{Comunicação do risco sanitário como poderosa ferramenta política: desafios}

Em 2018, o período pré-eleição a presidente do Brasil revelou como o Facebook, junto com outras mídias digitais, pode mediar a propagação em rede da desinformação e ampliar a (re)produção de inverdades. Apropriar-se destes espaços para as disputas de sentido no campo da saúde pública, portanto, é urgente e requer profissionalismo, ética, transparência e capacidade apurada de administrar conflitos o mais rapidamente possível.

Mesmo havendo a compreensão da importância de um processo dialógico, os modos de fazer comunicação do risco convocam uma série de enfrentamentos:

Comumente entendida como técnicas de transmissão de mensagens a serem "passadas", a comunicação "esbarra" no universo simbólico do outro, que ressignifica a mensagem. Nessa tensão de sentidos, de uma sociedade plural e assimétrica, as mensagens irão circular, podendo ganhar sentidos diferentes pelos distintos sujeitos da interação, resultando que, na sociedade brasileira com suas profundas desigualdades, a comunicação seja sempre um processo assimétrico. (Rangel-S, 2007b, p. 1383)
Guiadas por essas premissas, acredita-se que as políticas públicas de gerenciamento do risco devem adotar uma abordagem de comunicação do risco que aceite e envolva o público como parceiro legítimo (Rangel-S, 2007b). É mandatório, sobretudo, que o paradigma da regulação (pelo mercado, pelo Estado ou pela comunidade) seja substituído progressivamente pelo paradigma da emancipação, conforme sugerido por Paim (2007, p. 53). O autor alerta que, a pretexto de controlar produtos e serviços e de apoiar a comunicação, o Estado pode controlar informações para os cidadãos, domesticando-os, mediante prescrições neo-higienistas, o que muito se distancia do modelo emancipatório.

\section{As técnicas metodológicas deste estudo}

Trata-se de pesquisa qualitativa, de caráter descritivo-exploratório. É multimetodológica, combinando fundamentos da análise de redes sociais (ARS) com princípios da análise de conteúdo (AC).

A metodologia de ARS parte do princípio de que, ao estudar as estruturas decorrentes das ações e interações entre os atores sociais, é possível compreender elementos desses grupos e tecer generalizações a seu respeito (Fragoso; Recuero; Amaral, 2015). Partindo desse conceito, adotamos como atores as páginas de VS no Facebook e, a partir delas, diversas conexões puderam ser contabilizadas. Métricas referentes a reações, comentários e compartilhamentos foram consideradas conexões a analisar. Somadas, representam numericamente o engajamento atribuído a cada publicação ou postagem.

A técnica da AC pode ser dividida em três polos cronológicos: a pré-análise; a exploração do material; e o tratamento dos resultados, com inferência e interpretação (Bardin, 2016, p. 125). Essa abordagem analítica textual perpassa as etapas de codificação, categorização, enumeração, condensação, síntese, seleção e interpretação a partir da inferência. Neste trabalho, optamos por empregar a AC temática, de forma que as categorias reveladas apontassem os temas centrais das postagens da VS em suas páginas do Facebook. 
Mineração dos dados e identificação das categorias

\section{Primeira etapa: o mapeamento das páginas de vigilâncias sanitárias no Facebook}

Para a mineração dos dados utilizou-se o Netvizz, um aplicativo que permite que pesquisadores exportem dados em arquivos de formato padronizado a partir de diferentes seções da plataforma social (Rieder, 2012). As palavras "vigilância" e "sanitária" guiaram a busca por páginas, em 15 de janeiro de 2018. Assim, o Netvizz coletou qualquer página no Facebook que apresentasse ambas as palavras na composição de seu nome (título da página), na sua descrição ou no Uniform Resource Locator (URL), endereço da página na internet.

Os resultados geraram arquivos passíveis de conversão em planilhas de Excel. Organizada a relação de páginas resultantes da busca, conferiu-se a legitimidade de cada página, acessando-as no Facebook para analisar suas características identitárias.

As páginas excluídas encaixaram-se em algum dos seguintes critérios: (1) não apresentavam informações suficientes para autenticar sua relação com um órgão de VS; (2) correspondiam a organizações internacionais; (3) representavam grupos de interesse no assunto, como cursos de pós-graduação, mas sem relação direta com uma organização governamental; (4) pertenciam a profissionais de saúde ou empresas de consultoria; (5) consistiam em "páginas não oficiais" geradas pelo Facebook; com exceção da página não oficial da Anvisa, que foi mantida na análise.

\section{Segunda etapa: análise de conteúdo das publicações de vigilâncias sanitárias}

Foi realizada AC das postagens publicadas num período de seis meses, entre $1^{\circ}$ de junho e $1^{\circ}$ de dezembro de 2017 para duas páginas de VS: a da Agência Nacional de Vigilância Sanitária (Anvisa Oficial) e a da Vigilância Sanitária do município do Rio de Janeiro (Vigilância Sanitária Rio). Os critérios para seleção dessas páginas foram o destacado engajamento, no caso municipal, e o fato de representar a coordenação do SNVS, no caso da esfera federal. Para ambas as páginas, o risco sanitário foi o elemento central de análise das trinta postagens de maior engajamento.

As narrativas foram codificadas e categorizadas para a identificação do tema de cada postagem. A regra de enumeração frequencial simples foi empregada, assumindo que todos os temas teriam o mesmo valor na interpretação dos dados.

\section{Páginas de vigilância sanitária no Facebook: um mapeamento geral}

Foram identificadas 111 páginas de VS no Facebook. A grande maioria correspondeu à esfera municipal (104); somente três delas se associavam a VS estaduais; e uma única página relacionava-se à esfera federal. Embora três páginas apresentassem fortes indicações de representarem um órgão de VS, não foi possível encontrar evidências suficientes para indicar a VS responsável por mantê-las.

No caso federal, o Netvizz rastreou uma página não oficial da Anvisa; ao acessá-la, o Facebook sugeria o redirecionamento automático à página oficial da Agência. As métricas de todas as páginas de VS incluídas no estudo totalizam 61.895 fãs, 3.490 interações e 1.472 check-ins, incluindo a página não oficial da Anvisa.

A Tabela 1 ilustra o quantitativo das páginas de VS estaduais e municipais encontradas na pesquisa, dispostas por unidade federativa e suas respectivas métricas (número de fãs, de interações e de check-ins). Minas Gerais foi o estado que mais apresentou páginas de VS no Facebook, com um total de 13 páginas de VS municipal. O Rio Grande do Norte ficou em segundo lugar, com nove páginas ao todo, oito correspondentes a VS municipais e uma estadual, mais especificamente da Unidade Regional de Saúde Pública em Caicó. Empatados em terceiro lugar - com oito páginas de VS, todas da esfera municipal - ficaram os estados do Alagoas e do Paraná. Bahia, São Paulo e Rio de Janeiro totalizaram sete páginas de VS municipal cada, ocupando a quarta posição. Acre, Amapá, Roraima, Sergipe e Distrito Federal não apresentaram nenhuma página de VS no Facebook, seja da esfera municipal ou estadual. 
A diferença observada entre o número de páginas da esfera estadual e municipal poderia ser explicada pela própria organização político-administrativa do país. Ainda assim, outros argumentos da ordem política e de gestão precisam ser convocados para melhor explicar esse quadro. As únicas páginas de VS estaduais no Facebook pertencem à região
Nordeste (Rio Grande do Norte, Piauí e Paraíba). Esse dado pode indicar uma política regional para a comunicação por meio de mídias digitais, hipótese que motiva investigações futuras.

Quando agrupadas por região do país, as métricas analisadas destacam o Sudeste e o Nordeste (Gráfico 1 e Tabela 2).

Tabela I-Relação de páginas de vigilâncias sanitárias estaduais e municipais no Facebook e respectivas métricas

\begin{tabular}{|c|c|c|c|c|c|c|}
\hline UF & $\begin{array}{l}\text { Total de páginas } \\
\text { de vs }\end{array}$ & $\begin{array}{l}\text { Páginas de VS } \\
\text { municipal }\end{array}$ & $\begin{array}{l}\text { Páginas de VS } \\
\text { estadual }\end{array}$ & $\begin{array}{l}\text { Interações com } \\
\text { a página }\end{array}$ & Fãs & Check-ins \\
\hline $\mathrm{AL}$ & 8 & 8 & - & 115 & 1.688 & 2 \\
\hline$A M$ & 3 & 3 & - & 0 & 242 & 5 \\
\hline BA & 7 & 7 & - & 6 & 3.555 & $207^{*}$ \\
\hline CE & 6 & 6 & - & 3 & 561 & 33 \\
\hline DF & - & - & não se aplica & - & - & - \\
\hline ES & 1 & 1 & - & 0 & 51 & 0 \\
\hline GO & 4 & 4 & - & 4 & 2.114 & 15 \\
\hline MA & 3 & 3 & - & 2 & 806 & 7 \\
\hline MG & $13^{*}$ & $13^{*}$ & - & 44 & 3.519 & 28 \\
\hline MS & 2 & 2 & - & 16 & 356 & 9 \\
\hline MT & 4 & 4 & - & 2 & 1.245 & 4 \\
\hline PA & 3 & 3 & - & 4 & 371 & 0 \\
\hline PB & 5 & 4 & ।* $^{*}$ & 3 & 1.433 & 125 \\
\hline $\mathrm{PE}$ & 3 & 3 & - & 37 & 336 & 13 \\
\hline PI & 3 & 2 & ।* $^{*}$ & 5 & 533 & 147 \\
\hline PR & 8 & 8 & - & 12 & 1.403 & 6 \\
\hline RJ & 7 & 7 & - & $3.105^{*}$ & $35.575^{*}$ & 172 \\
\hline $\mathrm{RN}$ & 9 & 8 & ।* $^{*}$ & 20 & 1.778 & 6 \\
\hline RO & 2 & 2 & - & 1 & 280 & 0 \\
\hline RS & 3 & 3 & - & 15 & 489 & 1 \\
\hline SC & 5 & 5 & - & 3 & 398 & 0 \\
\hline SP & 7 & 7 & - & 55 & 1.929 & 51 \\
\hline TO & 1 & 1 & - & 6 & 157 & 0 \\
\hline
\end{tabular}

Tabela 2 - Somatório das métricas das páginas de vigilâncias sanitárias por região, Brasil, 15 de janeiro de 2018

\begin{tabular}{ccccc} 
Região & Interações com a página & Fãs & Check-ins & Somatório das métricas \\
Norte & 11 & 1.050 & 5 & 1.066 \\
Nordeste & 191 & 10.690 & 533 & 11.414 \\
Centro-Oeste & 22 & 3.715 & 28 & 3.765 \\
Sudeste & 3.204 & 41.074 & 251 & 44.529 \\
Sul & 30 & 2.290 & 7 & 2.327 \\
\hline
\end{tabular}


Gráfico I - Interações e fãs das páginas de vigilâncias sanitárias por região, Brasil, 15 de janeiro de 2018

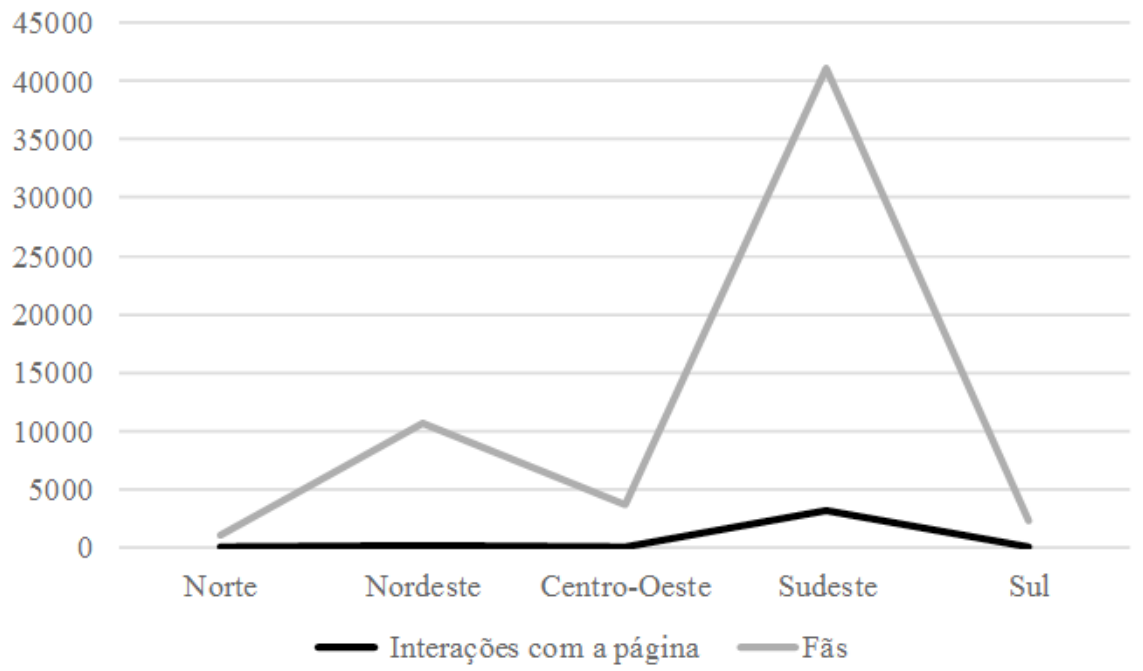

As páginas de VS da região Sudeste lideraram em número de fãs (41.074) e de interações (3.204), bem à frente da região Nordeste, cujas mesmas métricas a posicionam em segundo lugar. As contagens elevadas do Sudeste devem-se ao destaque alcançado pelo município do Rio de Janeiro. No momento da extração de dados, essa página contava com 33.367 fãs e 3.014 interações, $81 \%$ e $94 \%$ do total da região respectivamente.

Quando analisadas individualmente, muitas páginas de VS apresentaram pouquíssima ou nenhuma interação, apesar de um número considerável de fãs. Isso demonstra que a quantidade de fãs não representa, isoladamente, um KPI para monitorar a qualidade da comunicação no Facebook. Também indica que as mensagens publicadas por essas VS não foram suficientemente atraentes ao seu público a ponto de promover interações.

Dentre outras fragilidades observadas, podemos pontuar a ausência de informação na página sobre a localidade que a VS representa; a reduzida ou insuficiente interação com os usuários que se manifestam por meio de comentários às postagens; falta de resposta da VS mediante a publicação de mensagem que indica denúncia. Tais evidências revelam uma carência de planejamento e a necessidade de profissionalização, bem como salientam a necessidade de implementação de programas que integrem a complexidade dos temas de saúde com as não menos complexas práticas da comunicação.

\section{Páginas da Vigilância Sanitária Rio e Anvisa Oficial: potências e fragilidades das interações em rede por meio do Facebook}

A Tabela 3 demonstra algumas métricas das páginas selecionadas, computadas ao longo de seis meses, destacando-se o número total de publicações do período, a contagem de comentários, compartilhamentos, reações, curtidas e o engajamento.

Tabela 3 - Métricas geradas por todas as postagens das páginas Anvisa Oficial e Vigilância Sanitária Rio, entre I de junho e I de dezembro de 2017

\begin{tabular}{ccccccc} 
Página & $\begin{array}{c}\text { Total de } \\
\text { postagens }\end{array}$ & Comentários & Compartilhamentos & Reações & Curtidas & Engajamento \\
Anvisa Oficial & 238 & 15.220 & 31.392 & 35.883 & 32.631 & 82.495 \\
$\quad \begin{array}{l}\text { Vigilância } \\
\text { Sanitária Rio }\end{array}$ & 327 & 19.373 & 50.702 & 41.688 & 35.545 & 111.763 \\
\hline
\end{tabular}


No caso da Anvisa, cerca de 43,5\% das interações obtidas corresponderam a reações, sendo "curtida" a mais escolhida pelos usuários (90,9\%). Comentários e compartilhamentos representam $18,5 \%$ e $38,0 \%$ das interações, respectivamente. As interações registradas na página da VS municipal do Rio foram caracterizadas por $37,3 \%$ de reações (dentre as quais $85,3 \%$ curtidas); $17,3 \%$ de comentários e $45,4 \%$ de compartilhamentos. Somadas, as taxas de comentários e compartilhamentos ultrapassaram $60 \%$ de expressividade.

Mais da metade dos usuários de ambas as páginas, portanto, produziram um engajamento maior, expuseram-se mais na rede, na medida em que também tornaram públicas suas próprias narrativas, seja comentando ou compartilhando conteúdo. Ao compartilhar uma postagem, o usuário carrega o conteúdo produzido para sua própria página, podendo agregar textos adicionais a ele, o que potencializa a difusão das mensagens e acaba por gerar o "boca a boca digital" (Oliveira, 2016, p. 123).

Esse espalhamento da notícia pode ser providencial em termos de alcance das informações críticas em saúde, porém, sabe-se que essa maior exposição nem sempre é positiva e tampouco pode ser controlada. É muito importante, no entanto, que a reputação seja administrada em todos os detalhes, sendo primordial entender o lugar onde a credibilidade está depositada: no olhar e na percepção do público (Rosa, 2006 apud Oliveira, 2016). Juntamente com a construção da confiança, a reputação é muito importante para a implementação de uma política de comunicação do risco, como destacado por Rangel-S (2007b) e Lucchese (2001).

\section{A página Anvisa Oficial no Facebook: temas revelados}

Sete categorias foram desveladas por meio da AC, aqui listadas por ordem decrescente de engajamento: medicamento; curso; alimento; combate às superbactérias; reconhecimento e reputação da VS; e agrotóxico.

O tema medicamento concentrou o maior número de postagens $(17 ; 56,7 \%)$, com o maior somatório de engajamento (27.695 reações, comentários e compartilhamentos) dentre todas as categorias. A análise das postagens relacionadas revelou os subtemas: registro de medicamento na Anvisa; ações de regulamentação; vacinas; substâncias anorexígenas (sibutramina, anfepramona, femproporex e mazindol); uso de medicamentos controlados ("tarja preta") por estudantes interessados em melhorar o desempenho acadêmico; e ações de farmacovigilância.

$O$ registro de medicamentos obteve a maior proporção de engajamento, com aproximadamente 63,4\% (17.574) de todas as interações registradas nas postagens de medicamento. Destaca-se o registro do medicamento Spinraza que atingiu, com quatro publicações relacionadas ao assunto em seis meses, o maior engajamento da categoria. Uma única postagem relacionada ao processo de registro deste medicamento na Anvisa alcançou o segundo maior engajamento de todas as postagens analisadas no período, com 8.984 interações.

Diversos pacientes com atrofia muscular espinhal (AME), uma doença rara neuromuscular, encontravam-se sem opções terapêuticas no Brasil até a aprovação do registro do Spiranza (nusinersena) na Anvisa. Houve repercussão também em outras mídias sociais e mídias tradicionais online.

Em dezembro de 2017, o Ministério da Saúde informou que havia solicitado a avaliação da incorporação do medicamento no SUS pela Comissão Nacional de Incorporação de Tecnologias (Conitec) (Penido, 2017). Diante de tanta repercussão, pode-se acreditar que a manifestação popular incisiva, dentro e fora do Facebook, tenha influenciado a Anvisa a tratar a aprovação do Spinraza com prioridade, o que provocou, além de seu registro no Brasil, a abertura de consulta pública para a revisão de procedimentos relacionados ao registro de medicamentos de doenças raras.

Durante o processo de análise dessas postagens e suas interações, verificou-se que a Anvisa demonstra preocupação em elaborar respostas a comentários individuais publicados por usuários. Há alternância entre uma linguagem técnica, mais dura, e um discurso mais simples, colonizado por valores como empatia, compaixão e preocupação com o diálogo, recursos de capital social (Recuero, 2012) 
essenciais para uma comunicação pública eficiente na esfera digital.

Em segundo lugar, a categoria curso atingiu um engajamento de 25.186 interações, com apenas quatro postagens. Esse resultado indica a acentuada demanda por educação continuada nos assuntos de VS, especialmente no gerenciamento do risco sanitário.

A publicação que alcançou o maior engajamento (20.664 interações) de todas as postagens do período analisado divulga um "Curso de Introdução à Vigilância Sanitária gratuito e online”, destinado aos trabalhadores do SNVS e a qualquer interessado. Essa postagem não representa um comunicado de risco sanitário em si, mas mantém íntima relação com ele, uma vez que sua finalidade consistia em aprimorar a capacidade do profissional e do cidadão de identificar, analisar e intervir nos riscos de VS.

\section{A página Vigilância Sanitária Rio}

Cinco categorias foram identificadas por meio da AC, aqui dispostas por ordem decrescente de engajamento: (1) controle de zoonoses; (2) ações da VS no Rock in Rio; (3) operação Vigilância no Shopping; (4) resultados de inspeções em estabelecimentos que comercializam alimentos; e (5) capacitação profissional. Controle de zoonoses foi o tema mais citado, apareceu em 13 postagens (43\%). Somadas, as postagens com esta temática obtiveram o maior engajamento total: 40.946 reações, compartilhamentos e comentários. Isoladamente, a postagem de maior engajamento também se direcionou ao tema; abordou o controle da raiva como risco sanitário e atingiu, sozinha, 12.423 interações até o momento de extração dos dados.

Para o controle de zoonoses, os subtemas foram: (1) campanha de vacinação gratuita de cães e gatos contra raiva; (2) campanha de adoção de cães e gatos; (3) castração gratuita de cães e gatos no Instituto Jorge Vaitsman (IJV); ${ }^{5}$ (4) Mutirão de atendimento gratuito a animais com esporotricose no IJV; (5) comunicado esclarecendo que morcegos encontrados não apresentam riscos de mordeduras; e (6) melhorias na infraestrutura para atendimento de felinos no IJV.

A postagem de maior engajamento de todas as 30 publicações analisadas também abordou o controle de zoonoses. Publicada em 21 de agosto de 2017, a mensagem alertava para o início do programa de imunização antirrábica para cães e gatos do município do Rio de Janeiro. Até o momento da extração dos dados, essa publicação havia alcançado 12.423 interações, dentre as quais 10.053 compartilhamentos.

De fato, a raiva representa um "problema de saúde pública desde tempos imemoráveis” (Schneider et al., 1996, p. 197), e destinar investimentos para combatê-la é plenamente justificável, já que está relacionada a índices de letalidade próximos a $100 \%$, além da gravidade de sua sintomatologia e dos prejuízos econômicos e sociais relacionados à agricultura (Moutinho; Nascimento; Paixão, 2015; Sousa; Amaral; Gitti, 2014). Na cidade do Rio de Janeiro, o cão é a principal fonte de infecção (Sousa; Amaral; Gitti, 2014).

$\mathrm{O}$ alto número de interações para esta postagem pode ser explicado tanto pela importância do controle do vírus rábico em cães e gatos - enquanto interesse de saúde pública e gerenciamento do risco sanitário - quanto pela alta demanda por serviços veterinários gratuitos aos animais domésticos. É legítimo pensarmos que a consolidação do direito à saúde dependa da concretização de outros, como o direito ao tratamento digno de animais, sejam domésticos ou em situação de abandono. É uma relação paradoxal, pois um gato pode ser considerado de estimação ou um caso de zoonose (Baptistella; Abonizio, 2017).

Os comentários à postagem sobre a vacinação contra raiva revelam nuances da relação humana com cães e gatos, os quais são referenciados por usuários como "filhos" ou "bebês", ilustrando o forte vínculo que se constrói entre eles. Segundo relatórios,

\footnotetext{
5 A página Vigilância Sanitária Rio no Facebook é administrada pela Subsecretaria de Vigilância, Fiscalização Sanitária e Controle de Zoonoses (Subvisa), órgão responsável pelas ações de VS do município do Rio de Janeiro. Outras instituições estão vinculadas à Subvisa para complementar e executar as ações de promoção e proteção da saúde dos cariocas. O IJV é uma delas, com a função de executar serviços veterinários e ações de controle de zoonoses. Considerado referência para a vigilância em zoonoses no Brasil, completou 100 anos em 2017, o que desencadeou uma série de atividades voltadas à promoção da saúde no município.
} 
a relação dos brasileiros com os animais domésticos é cultural (Ipsos, 2017a) e precisa ser entendida com profundidade e respeito:

Animais de estimação incorporam uma saída emocional segura de relevância substancial na vida de muitas pessoas. Cuidar de animais de estimação é, muitas vezes, para os Millennials ${ }^{6}$ uma preparação para a paternidade ou maternidade e, às vezes, uma alternativa para eles. E para os pais de jovens adultos que finalmente estão deixando suas casas, é uma maneira de combater a síndrome do ninho vazio. (Ipsos, 2017b, tradução nossa)

Portanto, é esperado que modelos de comunicação e práticas de controle sanitário direcionem esforços à saúde de animais domésticos e sua relação com centros urbanos.

Nesta e em outras postagens, nota-se divulgação de link para redirecionamento à página da Prefeitura do Rio de Janeiro na web, onde são disponibilizadas informações complementares sobre a campanha. Esse recurso também é muito utilizado pela Anvisa em suas postagens. Assim, logra-se uma estética mais limpa e com menos caracteres, ideal para atrair a atenção do usuário conectado que se desloca constantemente enquanto lê e interpreta a mensagem. Tais adequações de formato, conteúdo e tamanho da postagem são condizentes com as necessidades da maioria dos brasileiros, que acessa a internet apenas por meio de seus celulares. As classes sociais menos favorecidas são as que mais acessam a internet exclusivamente por meio de smartphones (Cetic.br, 2016).

Finalmente, outro aspecto positivo observado sobre o uso das mídias sociais refere-se à reformulação do sistema de captação de denúncias. Além do método tradicional de registro de denúncias por telefone, a VS municipal do Rio de Janeiro ampliou a escuta ao "boca a boca" das redes sociais, ao considerar publicações de usuários que indicavam irregularidades sanitárias em estabelecimentos do município.

\section{Considerações finais}

É preciso aceitar que novas e revisitadas configurações comunicativas contemporâneas se concretizam por meio das mídias sociais e, caso a saúde pública não se aproprie deste espaço de discussão, outros o farão. As páginas de VS no Facebook representam importante ferramenta política e relevante espaço para problematização de questões inerentes aos riscos sanitários a que a sociedade está exposta.

Embora careçam de profissionalização para o desenvolvimento dessas atividades, tentativas de ocupar este espaço de debate interativo já existem. A marcada proatividade das VS analisadas em operar meios alternativos de informar sobre riscos e dialogar com a sociedade, por meio de suas páginas no Facebook, comprova isso. Tal atitude traduz um desejo comum da VS de ampliar o espectro comunicacional voltado à promoção da saúde. Por outro lado, observa-se um descompasso do SNVS quanto à implementação de um programa de comunicação via Facebook. A esfera municipal da VS protagoniza a comunicação mediada por esta plataforma social, havendo pouca expressão da esfera estadual na amostra pesquisada. A esfera federal ingressou tardiamente na mídia social mais popular no Brasil, preferindo ingressar antes no Twitter.

As diferenças observadas no engajamento dos cidadãos conectados certamente também é reflexo das diferenças socioeconômicas e culturais. A relação entre qualidade de acesso à internet e mobilidade reafirma as desigualdades existentes no país e precisa ser considerada no planejamento das políticas públicas que se destinem à comunicação digital. Por exemplo, o acesso à rede exclusivamente por meio de celular é mais frequente em áreas cuja infraestrutura para a internet fixa é precária, uma realidade para aqueles que residem nas regiões Nordeste (43\%), Norte (55\%) e nas áreas rurais (56\%) (Cetic.br, 2016, p. 145).

Administrar uma página no Facebook com a missão de proteção social é desafiador e coloca

6 Millennials ou geração Y: expressão utilizada para designar pessoas nascidas entre 1979 e 1995, muito empregada em estudos sobre consumidores e suas relações com empresas e marcas. 
à prova a capacidade de articulação da VS no ambiente digital e fora dele. Em muitas páginas de VS, manifestações de usuários permaneceram sem resposta, apontando essa fragilidade em administrar o conteúdo publicado, o que desintegra a oportunidade da relação em rede.

Exige-se, portanto, o desenvolvimento de uma série de competências, habilidades e experiências não inerentes ao exercício da função de fiscal ou gestor de VS. Uma equipe da área da comunicação precisa estar integrada à equipe de VS, alinhadas a uma política de comunicação do risco previamente discutida e aprovada.

Iniciativas como as identificadas na página Anvisa Oficial (no caso do medicamento Spinraza para tratamento de pacientes com AME) e na página da Vigilância Sanitária Rio (no caso de reformulação do sistema de apuração de denúncias) apontam para uma potência em comum: a reformulação dos mecanismos tradicionais de trabalho da VS, valorizando a inclusão da participação social na esfera digital.

No caso da Anvisa Oficial, o destacado engajamento para os assuntos relacionados ao tema medicamento endereçam importantes reflexões sobre a sociedade brasileira, bem como sobre o papel da Agência na forma de discutir saúde e comunicar riscos. Não por acaso, os medicamentos dão concretude às prioridades da comunicação pública no campo sanitário. A medicalização como resposta às necessidades de saúde deve ser debatida. Não se trata de negá-la como possibilidade, mas de manter aberto o debate sobre seus efeitos e implicações (Mutarelli, 2017, p. 228). Para aprofundarmos essa discussão, é necessário entender os contextos paradigmáticos em que travamos as discussões sobre as necessidades de saúde. Apreender o contexto em que nos situamos como sociedade de consumo é, portanto, compreender a medicalização como forma de biopoder (no entendimento foucaultiano), reflexo de uma sociedade globalizada, industrial e cada vez mais individualizada, sedimentada nos modos de viver e consumir do regime capitalista.

A comunicação envolvendo o registro de medicamentos como objeto é fortemente marcada por disputas no campo político, como foi possível notar no exemplo do Spinraza. 0 caso ilustrou como a pressão social estruturada em rede, em multiplataformas, pode ter influenciado para conferir agilidade e prioridade à pauta. A Anvisa utilizou o espaço interativo mediado pelo Facebook para incrementar mecanismos de participação social, convidando os usuários a participar de consulta pública relacionada aos medicamentos de doenças raras.

As postagens de maior engajamento da Vigilância Sanitária Rio apontam para a importância dada pelos cidadãos conectados ao tema do controle de zoonoses, o que revela fenômenos como o crescimento da população de cães e gatos, a ênfase aos movimentos de defesa dos animais e a importância da integralidade das ações de VS, como é possível notar nos casos de combate dos riscos relacionados à raiva e à esporotricose.

Em ambas as páginas nota-se preocupação em zelar pela reputação do trabalho desenvolvido pelas VS, o que é plenamente justificável para assegurar uma comunicação do risco que seja confiável, honesta e consistente. Em uma era de propagação em massa de notícias falsas (fake news), os mundos midiatizados do risco sanitário desafiam o poder de articulação do Estado, e a credibilidade das instituições públicas é posta em xeque.

Por fim, esta pesquisa demonstra que a comunicação da VS mediada pelas plataformas sociais pode usar as características da comunicação em rede para problematizar questões complexas de saúde.

Ao adotar a comunicação mediada por páginas no Facebook, a VS tem a oportunidade de captar interesses em disputa e ampliar a escuta para as demandas dos cidadãos conectados. Não se pode esquecer, no entanto, das desigualdades ainda existentes no acesso e uso desses espaços midiáticos por diferentes grupos sociais, o que nos leva a apostar em um somatório de espaços públicos para o debate, em complemento ao oportunizado pelas conexões digitais. Ou seja: "não basta preconizar o direito à saúde contido na forma da lei; este direito precisa tornar-se uma prática concreta no cotidiano dos serviços prestados à população" (Marins; Araújo; Jacob, 2014).

Ao assumir a conduta de midiatizar os riscos sanitários encontrados em uma inspeção, como faz a VS municipal do Rio de Janeiro (e tantas outras 
VS observadas durante esta pesquisa) no Facebook, assume-se o compromisso de problematizar questões de relevância em saúde pública e mediar o debate.

Os processos de comunicação do risco sanitário, como qualquer política pública, são moldados ao longo da vinculação e do conflito de interesses em disputa. Desvelar as distintas formas de poder, as forças motrizes existentes no tecido social provenientes dos campos político, social, econômico e cultural é de uma complexidade enorme, porém, de vital importância para organizar as prioridades que queremos evidenciar para conquistarmos a efetivação de direitos sociais, como o direito à saúde. Para isso, as ações da comunicação em VS precisam ser direcionadas para concretizar um modelo de comunicação do risco que coloque as pessoas em evidência, respeitando suas vulnerabilidades, modos de vida e identidades (Frazão; Minakawa, 2018).

Mesmo diante de muitas falhas nos processos dialógicos e participativos na esfera digital, as iniciativas analisadas neste trabalho nos permitem acreditar que é possível (e necessário) traduzir as relações geradas entre VS e sociedade conectada em novas formas de promover saúde. A partir disso, pode-se incrementar os meios de proteção social para fortalecer o direito à informação e, consequentemente, consolidar o direito à saúde.

\section{Referências}

BAPTISTELLA, E.; ABONIZIO, J. O peso dos animais nas urnas: uma reflexão sobre o papel dos animais na política contemporânea. Revista Brasileira de Ciência Política, Brasília, DF, n. 22, p. 329-372, 2017.

BARDIN, L. Análise de conteúdo. São Paulo: Edições 70, 2016.

BRASIL. Constituição da República Federativa do Brasil. Diário Oficial da União, Brasília, DF, 5 out. 1988. Disponível em: <http://bit. ly/38AidvQ>. Acesso em: 30 ago. 2018.

BRASIL. Lei no 8.078, de 11 de setembro de 1990. Dispõe sobre a proteção do consumidor e dá outras providências. Diário Oficial da União, Brasília, DF, 12 set. 1990a. Disponível em:
<http://bit.ly/39Dauhc>. Acesso em: 18 set. 2018.

BRASIL. Lei no 8.08o, de 19 de setembro de 1990. Dispõe sobre as condições para a promoção, proteção e recuperação da saúde, a organização e o funcionamento dos serviços correspondentes e dá outras providências. Diário Oficial da União, Brasília, DF, 20 set. 199ob. Disponível em:

<http://bit.ly/2uC3SRl>. Acesso em: 18 set. 2018.

BRASIL. Lei n ${ }^{0}$ 9.782, de 26 de janeiro de 1999. Define o Sistema Nacional de Vigilância Sanitária, cria a Agência Nacional de Vigilância Sanitária, e dá outras providências. Diário Oficial da União, Brasília, DF, 27 jan. 1999. Disponível em:

<http://bit.ly/2HqtMtP>. Acesso em: 18 jul. 2018.

BRASIL. Presidência da República. Secretaria de Comunicação Social. Pesquisa brasileira de mídia 2015: hábitos de consumo de mídia pela população brasileira. Brasília, DF: Secom, 2014. Disponível em: <http://bit.ly/2UVn8np>. Acesso em: 20 jul. 2018.

CETIC.BR - CENTRO REGIONAL DE ESTUDOS PARA O DESENVOLVIMENTO DA SOCIEDADE DA INFORMAÇÃO. TIC Domicílios 2015: pesquisa sobre o uso das tecnologias de informação e comunicação nos domicílios brasileiros. São Paulo: Comitê Gestor da Internet no Brasil, 2016. Disponível em: <http:// bit.ly/2SpLT9I>. Acesso em: 18 jul. 2018.

CORRÊA, E. S. Centralidade, transversalidade e resiliência: reflexões sobre as três condições da contemporaneidade digital e a epistemologia da Comunicação. In: CONGRESSO INTERNACIONAL IBERCOM, 14., 29 mar.-2 abr. 2015, São Paulo. Anais... São Paulo: ECA/USP, 2015. Não paginado.

FIGUEIREDO, A. Caminhos da vigilância sanitária brasileira: proteger, vigiar, regular. São Paulo: Hucitec, 2016.

FRAGOSO, S.; RECUERO, R.; AMARAL, A. Métodos de pesquisa para internet. Porto Alegre: Sulina, 2015. 
FRAZÃO, P.; MINAKAWA, M. M. Medicalização, desmedicalização, políticas públicas e democracia sobre o capitalismo. Trabalho, Educação e Saúde, Rio de Janeiro, v. 16, n. 2, p. 407-430, 2018.

IPSOS. Brasil 2018: caiu a máscara! A hora da verdade. São Paulo, 2017a. Disponível em: <http://bit.ly/2SsME1V>. Acesso em: 9 mar. 2018.

IPSOS. Brazil 2018: the mask slipped! Time for truth: 10 key points. São Paulo, 2017b. Disponível em: <http://bit.ly/3bCItIi>. Acesso em: 9 mar. 2018.

JANES, M. W.; MARQUES, M. C. C. A contribuição da comunicação para a saúde: estudo de comunicação de risco via rádio na Grande São Paulo. 2007. Dissertação (Mestrado em Saúde Pública) - Universidade de São Paulo, São Paulo, 2007.

KEMP, S. Digital in 2018: world's internet users pass the 4 billion mark. We are Social, Hootsuite, 30 jan. 2018. Disponível em: <http://bit.ly/2UR5CAI>. Acesso em: 4 ago. 2018.

KEMP, S. Digital in 2020: global digital overview. We are Social, Hootsuite, jan. 2020. Disponível em: <https://bit.ly/2PtEglo>. Acesso em: 20 fev. 2020.

LUCCHESE, G. Globalização e regulação sanitária: os rumos da vigilância sanitária no Brasil. 2001. Tese (Doutorado em Saúde Pública) - Fundação Oswaldo Cruz, Rio de Janeiro, 2001.

MARINS, B. R.; ARAÚJO, I. S.; JACOB, S. C. Vigilância sanitária e direito à comunicação: a rotulagem de alimentos como espaço de cidadania. Vigilância Sanitária em Debate, Rio de Janeiro, v. 2, n. 4, p. 86-95, 2014.

MOUTINHO, F. F. B.; NASCIMENTO, E. R.; PAIXÃO, R. L. Raiva no estado do Rio de Janeiro, Brasil: análise das ações de vigilância e controle no âmbito municipal. Ciência \& Saúde Coletiva, Rio de Janeiro, v. 20, n. 2, p. 577-586, 2015.
MUTARELLI, A. Estratégias de resistência à medicalização: a experiência francesa. 2017. Tese (Doutorado em Psicologia) - Universidade de São Paulo, São Paulo, 2017.

NEIGER, B. L. et al. Evaluating social media's capacity to develop engaged audiences in health promotion settings: use of Twitter metrics as a case study. Health Promotion Practice, Thousand Oaks, v. 14, n. 2, p. 157-162, 2013. OLIVEIRA, M. Gestão de crises em mídias sociais. In: SILVA, T.; STABILE, M. (Org.). Monitoramento e pesquisa em mídias sociais: metodologias, aplicações e inovações. São Paulo: Uva Limão, 2016. p. 121-132.

PAIM, J. S. Formulação de políticas de saúde: comunicação em vigilância sanitária. In: COSTA, E. A.; RANGEL-S, M. L. (Org.). Comunicação em vigilância sanitária: princípios e diretrizes para uma política. Salvador: Edufba, 2007. p. 41-55

PENIDO, A. Ministério da Saúde comprará medicamento Spinraza para atender ações judiciais. Agência de Saúde, 19 dez. 2017. Disponível em: <http://bit.ly/37mspqI >. Acesso em: 30 abr. 2018.

RANGEL-S, M. L. Risco, cultura e comunicação na proteção e promoção da saúde. In: COSTA, E. A.; RANGEL-S, M. L. (Org.). Comunicação em vigilância sanitária: princípios e diretrizes para uma política. Salvador: Edufba, 2007a. p. 95-114.

RANGEL-S, M. L. Comunicação no controle de risco à saúde e segurança na sociedade contemporânea: uma abordagem interdisciplinar. Ciência \& Saúde Coletiva, Rio de Janeiro, v. 12, n. 5, p. 1375-1385, 2007b.

RECUERO, R. O capital social em rede: como as redes sociais na internet estão gerando novas formas de capital social. Contemporânea: Comunicação e Cultura, Salvador, v. 10, n. 3, p. 597-617, 2012.

RECUERO, R.; SOARES, P. Violência simbólica e redes sociais no Facebook: o caso da fanpage “Diva Depressão". Galaxia, São Paulo, n. 26, p. 239-254, dez. 2013. 
RIEDER, B. Studying Facebook via data extraction: the Netvizz Application. The Politics of Systems, Amsterdam, p. 1-10, 2012. Disponível em: <http://bit.ly/37qLNTt $>$. Acesso em: 15 jan. 2018.

SCHNEIDER, M. C. et al. Controle da raiva no Brasil de 1980 a 1990. Revista de Saúde Pública, São Paulo, v. 3o, n. 2, p. 196-203, 1996.

SOUSA, P. G.; AMARAL, B. M. P. M.; GITTI, C. B. Raiva animal na cidade do Rio de
Janeiro: emergência da doença em morcegos e novos desafios para o controle. Revista do Instituto Adolfo Lutz, São Paulo, v. 73, n. 1, p. 119-124, 2014.

VECINA NETO, G.; MARQUES, M. C. C.; FIGUEIREDO, A. M. Vigilância sanitária no Brasil. In: CAMPOS, G. W. S. et al. (Org.). Tratado de saúde coletiva. São Paulo: Hucitec; Rio de Janeiro: Fiocruz, 2006. p. 689-713.

\section{Contribuição das autoras}

Voos concebeu e redigiu o manuscrito, coletou $e$ interpretou os dados, formatou imagens e tabelas, submeteu e adequou o artigo às normas da revista. Marques orientou a pesquisa acadêmica inicial e participou da revisão crítica e revisão final deste artigo.

Recebido: 19/12/2018

Aprovado: 26/09/2019 